\title{
Análisis Funcional
}

\section{Instrucciones}

Para el entrevisdador EI FAST identifica factores que pueden influenciar los problemas de conducta. Utilice el FAST sólo como parte de la evaluación previa a un análisis funcional de la conducta exhaustivo. Administre el FAST a varios individuos que se relacionen con frecuencia con el cliente. A continuación, utilice los resultados para orientar la observación directa en varias situaciones a fin de verificar las presuntas funciones de la conducta e identificar otros factores que puedan influir en el problema de conducta.

Para el informador Complete las siguientes secciones. A continuación conteste cuidadosamente cada pregunta y responda rodeando "Sí" o "No". Si no está seguro de una respuesta, seleccione "NP" (no procede).

\section{Cliente}

Fecha

\section{Informador}

Entrevistador

\section{Relación entre el informador y el cliente}

1. Indique su relación con la persona

\section{Padre / Madre}

Instructor / Maestro

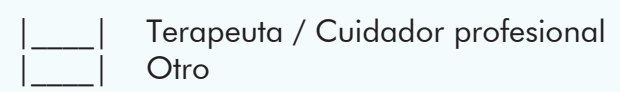

2. ¿Cuánto tiempo hace que conoce a la persona?

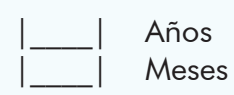

3. ¿Se relaciona Usted con la persona todos los días?
Sí
No

4 ¿̇En qué situaciones se relaciona Usted con la persona habitualmente?

\section{Comidas}

Actividades escolares

Ocio
Trabajo o formación ocupacional Actividades relacionadas con el cuidado personal Otras 


\title{
Información sobre el problema de conducta
}

1. Problema de conducta (marque y describa):

\author{
Agresión \\ Autolesión \\ Estereotipias \\ Destrucción de objetos \\ Otro
}

2. Frecuencia:
Cada hora
Diaria
Semanal
Baja frecuencia

3. Gravedad

Leve: La conducta interfiere, pero es de bajo riesgo

Moderada: Daños o lesiones menores

Grave: La conducta supone una amenaza significativa a la salud o la seguridad

4. Situaciones en las que es más probable que ocurra el problema de conducta

Días / Horas

Lugar / Actividades

Personas presentes

5. Situaciones en las que es menos probable que se produzca el problema de conducta Días / Horas

Lugar / Actividades

Personas presentes

6. ¿Qué sucede normalmente antes de que se produzca el problema de conducta?

7. ¿QQué sucede normalmente después de que se produzca el problema de conducta?

8. Tratamientos actuales 


\section{Social: acceso a atención o artículos preferidos}

1 ¿Se produce el problema de conducta cuando la persona no está recibiendo atención o cuando sus cuidadores están prestando atención a otra persona?

\section{SI

2 ¿Se produce el problema de conducta cuando las peticiones de la persona relativas a artículos o actividades deseadas le son denegadas o cuando éstos objetos o actividades se retiran?

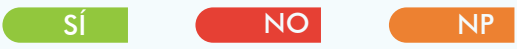

3 Cuando se produce el problema de conducta, ¿̇suelen los cuidadores tratar de calmar a la persona o tratan de que la persona realice actividades preferidas?

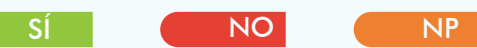

4 Por lo general, ¿̇se comporta bien la persona cuando está recibiendo mucha atención, o cuando tiene libre acceso a actividades preferidas?

\section{Social: escape de tareas o actividades}

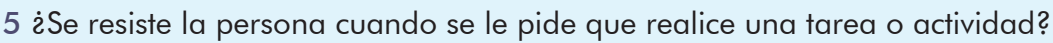

Sí No

6 ¿Se produce el problema de conducta cuando se le pide a la persona que realice una tarea o que participe en actividades?

7 Si se produce el problema de conducta mientras se le están presentando tareas, ¿̇se le suele dar un descanso de las tareas?

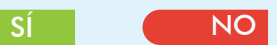

8 Por lo general, ¿̇se comporta la persona bien cuando no se le pide que haga nada?

\section{Automático: estimulación sensorial}

9 ¿̇e produce el problema de conducta, incluso cuando no hay nadie cerca o nadie le está viendo?

10 ¿́La persona realiza el problema de conducta incluso cuando hay actividades de ocio disponibles?

$$
\text { Sí }
$$

11 ¿Aparece el problema de conducta como una forma de "auto-estimulación"?

12 ¿̇Es el problema de conducta menos probable cuando hay actividades presentes que producen estimulación sensorial? 


\section{Automático: atenuación del dolor}

13 ¿Es el problema de conducta cíclico? Es decir, ocurre durante varios días y luego se detiene.

14 ¿La persona padece condiciones dolorosas tales como infecciones del oído o alergias? En caso afirmativo, indique cuál:

15 ¿̇Es el problema de conducta más probable cuando la persona está enferma?

\section{sí NO}

16 Si la persona está experimentando problemas físicos, y éstos son tratados, ¿̇desaparece el problema de conducta?

\section{Puntuación}

Rodee el número de cada pregunta en la que se respondió "Sí" y escriba el número de elementos que fueron rodeados en la columna "Total".

Ítems con respuesta afirmativa ("Si") Total $\quad$ Fuente potencial de reforzamiento

$\begin{array}{cccc}1 & 2 & 3 & 4 \\ 5 & 6 & 7 & 8 \\ 9 & 10 & 11 & 12 \\ 13 & 14 & 15 & 16\end{array}$

Social (atención / artículos preferidos)

Social (escape de tareas / actividades)

Automático (estimulación sensorial)

Automático (atenuación del dolor)

\section{Condiciones de uso}

La versión en español de la escala Functional Analysis Screening Tool (FAST) es distribuida gratuitamente por ABA España con permiso expreso del autor original. Este documento es una traducción precisa del original (fuente citada a continuación). Esta versión traducida no ha sido objeto de estudios directos de fiabilidad y validez. El uso de esta escala debe hacerse observando en todo caso las siguientes condiciones: (1) no está permitido realizar ningún cambio en el contenido o forma de este documento, (2) no esta permitida la redistribución de este documento o de una versión modificada de este documento, no obstante, el usuario puede compartir la fuente original en internet de este documento (ver sección Citar este documento), (3) cualquier referencia a la escala FAST en español debe citar expresamente a sus autores (ver sección Citar este documento), y (4) el uso de esta escala requiere que el usuario esté familiarizado con la metodología del análisis funcional experimental y, especialmente, con la investigación empírica asociada a esta escala y que está citada a continuación.

Fuente Iwata, B. A., DeLeon, I. G., y Roscoe, E. M. (2013). Reliability and validity of the Functional Analysis Screening Tool. Journal of Applied Behavior Analysis, 46, 271-284. https://doi.org/10.1002/jaba.31 (Reproducido con permiso del autor). 


\section{Terms of use}

The Spanish version of the Functional Analysis Screening Tool (FAST) is distributed freely by ABA España with expressed permission from the author. This is a precise translation of the original (source cited below). This translated version has not been the subject of direct reliability and validity studies. The scale use must be conducted under strict observance of the following conditions: (1) any changes to the contents or form of this document is strictly forbidden; (2) redistributing this document or a modified version of this document is strictly forbidden, users may disseminate the original internet source of this document (see section Citar este documento); (3) any reference to the Spanish version of the FAST should explicitly cite its authors (see section Citar este documento); and (4) users should be familiar with the scale's supporting research cited below.

Source Iwata, B. A., DeLeon, I. G., \& Roscoe, E. M. (2013). Reliability and validity of the Functional Analysis Screening Tool. Journal of Applied Behavior Analysis, 46, 271-284. https://doi.org/10.1002/jaba.31 (Reproduced with permission by author).

\section{Citar este documento}

Iwata, B. A., DeLeon, I. G., \& Roscoe, E. M. (2020). Instrumento de Cribado para Análisis Funcional (Functional Analysis Screening Tool, FAST), versión en español (J. Virues-Ortega, trad.). ABA España. https://doi.org/10.26741/2020.fast

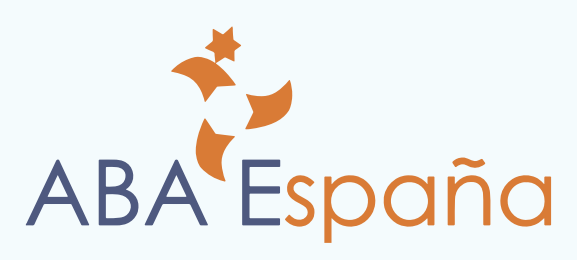

